\title{
Prevalence and Associated Factors of Diabetic Foot at Risk among Type 2 Diabetes Mellitus Patients Attending Primary Health Clinics in Kuantan.
}

\author{
Azmi $\mathrm{NH}^{a}$, Abdul Hadi $A^{a}$, Md Aris $M A^{a}$, Nasreen $\mathrm{HE}^{b}$, Che-Ahmad $A^{c}$ \\ ${ }^{a}$ Department of Family Medicine, International Islamic University Malaysia \\ bepartment of Community Medicine, International Islamic University Malaysia \\ 'Department of Orthopaedics, Traumatology and Rehabilitation, International Islamic University Malaysia
}

\section{ABSTRACT}

Introduction: The diabetic foot at risk is the diabetic foot which is at risk of ulceration, hence the importance of identifying the foot at this stage. This study aims to assess the prevalence of diabetic foot at risk and its associated factors among type 2 diabetes mellitus patients' attending primary health clinics in Kuantan. Methods and methods : This was a cross-sectional study conducted at four primary health clinics in Kuantan involving 450 study participants who were selected by using universal sampling method. Foot examination was carried out and foot at risk was classified based on the Kings' Classification. Multiple logistic regressions were performed to identify the predictors for diabetic foot at risk. Results: The prevalence of diabetic foot at risk was 31.3\%. Multivariate logistic regression analysis identified age (OR 1.04, 95\% Cl: 1.01-1.06), smoker (OR 4.11, 95\% Cl: 1.96-8.63) and duration of diabetes more than 10 years (OR1.77, 95\% Cl: 1.05-2.98) as risk factors for diabetic foot at risk. Respondents with higher diabetic foot practice score (OR 0.87, 95\% Cl: 0.77-0.98) have lesser risk of developing diabetic foot at risk. Conclusion: Patients who are older, smoker and/or have chronic diabetes are predicted to be at higher risk to develop the diabetic foot at risk. This study also showed that patients with better foot care practice has lesser risk. Therefore, these are the groups of patients that need to be targeted for early detection and intervention to prevent serious complications.

KEYWORDS: Prevalence, Diabetes, Foot at risk, Primary health clinic, Malaysia

\section{INTRODUCTION}

Diabetes is a major cause of blindness, kidney failure, According to the latest update from WHO (2016), an heart attack, stroke and lower limb amputation. ${ }^{1}$ In estimated 422 million people globally were living diabetic patients, the most common and debilitating with diabetes in 2014, compared to 108 million in complication is peripheral neuropathy, of which $70 \%$ affect the foot. ${ }^{2}$ It is also classified under one of the metabolic diseases and one of four priority of noncommunicable disease that had given biggest impact to the health, social and economic status worldwide. The Malaysian National Health and Morbidity It is a common and potentially disabling chronic Survey (NHMS) 2015 meanwhile states that the disease worldwide. ${ }^{1}$

Corresponding Author:

Asst. Prof. Dr Azwanis Abdul Hadi, Department of Family Medicine, International Islamic University Malaysia, 25200, Kuantan, Pahang, Malaysia.

Tel No : +6095704582

Email : azwanis@iium.edu.my
1980. The global prevalence of diabetes also showed double increment since 1980 from $4.7 \%$ to $8.5 \%$ in the adult population. ${ }^{1}$

overall prevalence of diabetes mellitus (known and undiagnosed) among adults of 18 years and above was $17.5 \%$ (95\% Cl: $16.6,18.3)$. There was an overall increasing trend in the $18-19$ years age group $5.5 \%$ (95\% Cl: $3.9,7.7)$ and among the $70-74$ years age group $39.1 \%(95 \% \mathrm{Cl}: 33.6,44.9){ }^{8}$

The annual incidence of foot ulcer in the general population was $2.2-5.9 \%$ and the prevalence was 
lower $(1.7 \%-3.3 \%)$ in younger patients with either type 1 or type 2 diabetes and higher (5-10\%) in older individuals with mainly type 2 diabetes. This is due to non-healing ulcer, where the recurrent rate is high. ${ }^{23}$

The biggest problem in combating the illness is because of the lack of awareness regarding symptoms, risk factors and early screening for diabetic foot. These lead to untreated, late detection or poor care of a diabetic foot ulcer that consequently could lead to limb amputation. This is really devastating as it can cause the loss of function in society as well as the high economic demand for treatment, rehabilitation and prosthesis. ${ }^{9}$

Diabetic foot at risk is very important to recognize as it has high potential to ulcerate or become infected which could lead to amputation. ${ }^{10}$ The three main factors involved in diabetic foot complications are neuropathy, infection, and ischemia. Most of foot problems result from a complex interplay among all three and possibly other factors such as altered foot pressures, limited joint mobility, glycemic control and ethnic background. ${ }^{4}$ Poor blood flow to the feet that could lead to ischemia. It causes delay in wound healing and chronic infection that later on could lead to gangrene. Gangrene and foot ulcers that do not get better with treatment can lead to amputation of the affected limb. Thus, good foot care is very important to prevent serious infections and gangrene. ${ }^{4}$

Many studies focused on the diabetic foot ulcer rather than the foot at risk itself. This leads to a gap in identifying risk factors for foot at risk in order to prevent complications such as ulcer and amputation. There are many commonly used classifications and each has its advantages and disadvantages. ${ }^{25} \mathrm{~A}$ good classification system takes into account the major risk factors involved in causing a diabetic foot problem such as vasculopathy, neuropathy and immunopathy. Such a classification system serves to provide good guidelines for the management of these problems. There are many classification systems that classify ulcers. These include the Wegner Meggitt Wound Classification and the University of Texas Wound Classification. The King's classification, designed in 2000, takes into account other clinical features of the diabetic foot, such as cellulitis and gangrene. ${ }^{25}$

This study use Kings College Classification as it is simple and able to stratify foot problem based on the stages of foot problem especially in identifying foot at risk other than focusing only on foot ulcer. This classification also was recommended by our current local guideline in addition to the Texas classification. In Kings College Classification, foot at risk falls under stage 2 which is defined as patient who develop one or more risk factors for diabetic foot including ischemia, neuropathy, callus, deformity or swelling. ${ }^{3}$ There was a local study done by Che Ahmad et al (2012) in different clinical setting that exert a significant result in prevalence of foot at risk. ${ }^{6}$

The purpose of this study is to identify the prevalence and risk factors for diabetic foot at risk and its association with the level of awareness and practice. This will enable us to plan for strategic approach to empower good diabetic foot care service and organize appropriate programme to create awareness and training in proper foot care practice in the future.

\section{METHODS AND MATERIALS}

\section{Study design, population and sampling method}

This is a cross sectional study of diabetic foot at risk among Type 2 Diabetes Mellitus patients aged more than 18 years old from four primary health clinics in Kuantan registered under the National Diabetes Registry. The study was conducted from December 2017 to November 2018. A sample size of 450 was calculated using the prevalence of diabetic foot at risk as $57.7 \%$ with relative precision of $1 \%$ and dropout rate of $20 \%$. Universal sampling method was used whereby all T2DM patients age more than 18 years old and on regular follow up at government primary health clinic were selected until reached the sample size. Patients with diabetic foot problem under orthopedic clinic follow up and fall within King's classification stage 3 and above of diabetic foot problem were excluded from the study.

\section{Study instrument}

Study instruments used were a clinical foot assessment form adapted with permission from Che Ahmad et al. (2012) where dermatological, neurological and vascular assessment were carried out and classified based on the King's Classification. ${ }^{6}$ Based on Kings Classification, Stage 2 or foot at risk includes diabetic foot with ischemia, neuropathy, callus, deformity or swelling. Patients were examined for these risk factors. 
Patients were also given a set of self-administered questionnaire on Awareness of foot problem and Foot Care practice. The questionnaire was validated and translated into the local language by previous researcher. $^{5}$

\section{Statistical analysis}

Data collected in this study was analyzed using Statistical Package for Social Science (SPSS) version. ${ }^{23}$ Descriptive analysis was used for respondent's socio-demographic data. Categorical variables were summarized into frequency and proportion. Chi square and independent t-test was used to find the association between categorical data. Multiple logistic regressions was used to assess predictors of the foot at risk after controlling confounders.

\section{Ethical consideration}

Ethical approval to conduct this study was obtained from the local university's ethics committee (IREC 2017-078) as well as the local medical research ethics committee (MREC: NMRR-17-2309-37038).

\section{RESULTS}

\section{Sociodemographic factors}

The respondents' mean age was $56.36(\mathrm{SD} \pm 10.9)$ years with the youngest being 28 years old and the eldest was 82 years old. Majority of the respondents were female (56.4\%), Malay $(85.1 \%)$, married $(93.1 \%)$, with secondary level of education (53.3\%) and from low income group (60.7\%). Background characteristics of respondents are shown in Table 1.

\section{Behavioural factors}

Majority of the respondents (90.9\%) were non-smoker (non-smoker include respondents who never smoked and ex- smoker at the time of study). However, among the respondents who do smoke, $73.2 \%$ had smoked for more than 10 years.

\section{Clinical factors}

The majority of respondents $(79.8 \%)$ were diagnosed with diabetes for $\leq 10$ years and were on non-insulin therapy $(63.1 \%)$. Despite this, $78.9 \%$ of them had uncontrolled diabetes. Only $9.8 \%$ of the patients had normal BMI and more than half $(59.3 \%)$ of the respondents were obese.

Background characteristics of respondents were shown in Table 1.

Table 1: Background Characteristics of Respondents $(\mathrm{n}=450)$

\begin{tabular}{|c|c|c|}
\hline $\begin{array}{l}\text { Background } \\
\text { characteristics }\end{array}$ & Mean (s.d.) & $\begin{array}{l}\text { Frequency } \\
\text { (\%) }\end{array}$ \\
\hline \multicolumn{3}{|l|}{$\begin{array}{l}\text { SOCIO-DEMOGRAPHIC } \\
\text { FACTORS }\end{array}$} \\
\hline Age (years) & $56.36( \pm 10.895)$ & \\
\hline \multicolumn{3}{|l|}{ Gender } \\
\hline Male & & $196(43.6)$ \\
\hline Female & & $254(56.4)$ \\
\hline \multicolumn{3}{|l|}{ Ethnicity } \\
\hline Malay & & $383(85.1)$ \\
\hline Chinese & & $37(8.2)$ \\
\hline Indian & & $26(5.8)$ \\
\hline Others & & $4(0.9)$ \\
\hline \multicolumn{3}{|l|}{ Marital status } \\
\hline Married & & $419(93.1)$ \\
\hline Single & & $23(5.1)$ \\
\hline Divorced & & $8(1.8)$ \\
\hline \multicolumn{3}{|l|}{ Educational status } \\
\hline No formal education & & $27(6.0)$ \\
\hline Primary education & & $99(22.0)$ \\
\hline Secondary education & & $240(53.3)$ \\
\hline Higher education & & $84(18.7)$ \\
\hline \multicolumn{3}{|l|}{ Income } \\
\hline$<$ RM 2300 & & $273(60.7)$ \\
\hline RM 2300 - RM 5599 & & $138(30.7)$ \\
\hline >RM 5599 & & $39(8.70)$ \\
\hline \multicolumn{3}{|l|}{ BEHAVIOURAL FACTOR } \\
\hline Non smoker & & 409(90.9) \\
\hline Smoker & & $41(9.10)$ \\
\hline \multicolumn{3}{|l|}{ Duration of smoking } \\
\hline$(n=41)$ & & $3(7.30)$ \\
\hline$<5$ years & & $8(19.5)$ \\
\hline 5-10 years & & $30(73.2)$ \\
\hline$>10$ years & & \\
\hline \multicolumn{3}{|l|}{ CLINICAL FACTORS } \\
\hline Duration of diabetes & & $359(79.8)$ \\
\hline$\leq 10$ years & & $91(20.2)$ \\
\hline \multicolumn{2}{|l|}{$>10$ years } & $95(21.1)$ \\
\hline Diabetes Control & & $355(78.9)$ \\
\hline \multicolumn{3}{|l|}{ Controlled } \\
\hline \multicolumn{3}{|l|}{ Uncontrolled } \\
\hline & & $284(63.1)$ \\
\hline Mode of treatment & & $166(36.9)$ \\
\hline \multicolumn{3}{|l|}{ Non- Insulin } \\
\hline \multicolumn{3}{|l|}{ Insulin } \\
\hline Body Mass Index & & $44(9.8)$ \\
\hline $\operatorname{Normal}(\leq 22.99)$ & & $139(30.9)$ \\
\hline Overweight $(\geq 23.00)$ & & $267(59.3)$ \\
\hline Obese $(\geq 27.5)$ & & \\
\hline
\end{tabular}




\section{Prevalence of diabetic foot at risk}

The prevalence of foot at risk among respondents was $31.3 \%$ as shown in Table 2. Figure 1 summarized the clinical finding among respondents who had foot at risk, $85.1 \%$ of them had dermatology abnormality/ deformity such as bunion, Charcot's joint etc. while the rest had neuropathy $(8.5 \%)$ and vascular abnormality $(6.45 \%)$.

Table 2: Foot Assessment Using King's Classification of Respondents $(n=450)$

\begin{tabular}{llll}
\hline $\begin{array}{l}\text { Foot assessment } \\
\text { (King's Classification) }\end{array}$ & Frequency & (\%) \\
\hline Normal & 309 & 68.7 \\
Foot at risk & 141 & 31.3 \\
\hline
\end{tabular}

\section{Awareness and Practice Level}

Both awareness and practice are factors which are statistically significant with the development of diabetic foot at risk ( $p$ value $<0.05$ ) as shown in Table 3. Regarding the awareness level, respondents with diabetic foot at risk were found to have scores higher than the mean. This means that respondents with diabetic foot at risk are aware of the problems related with diabetic foot problem. However, when it comes to practice, respondents with diabetic foot at risk attained lower score than the mean; which shows that they have poor foot care practice.

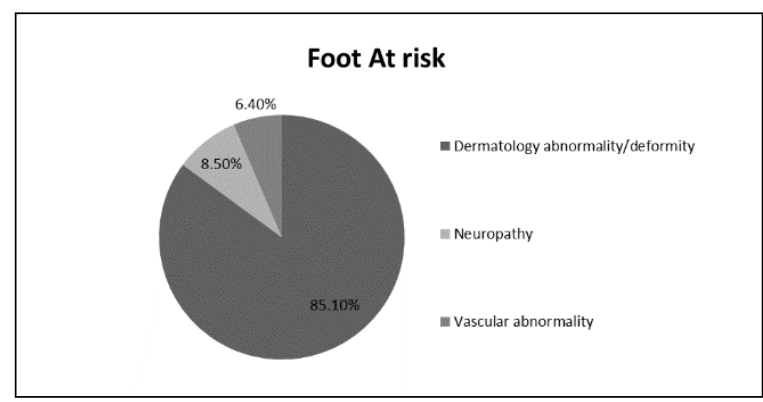

Figure 1: Clinical findings among respondents with foot at risk $(n=141)$

Factors associated with diabetic foot at risk (bivariate analysis)

Table 3 shows the background characteristics associated with diabetic foot at risk. Based on these, the factors that are significantly associated with diabetic foot at risk are age, race, smoking status, duration of diabetes, awareness and practice level. All factors in bivariate analysis that had $\mathrm{p}$ value of < 0.25 and clinically important were further analyzed using logistic regression to look for factors that had significant association with development of diabetic foot at risk after controlling all variables.
Factors associated with diabetic foot at risk (multivariate analysis).

In multivariate analysis (Table 4), statistically significant predictive factors identified for diabetic foot at risk after controlling other variables were age, smoker, diabetes duration and level of practice. It showed that for every one-year increment in age, there is a one-time risk of developing diabetic foot at risk (OR 1.04, 95\% Cl: 1.01-1.06) after controlling for other variables. A smoker is four times more likely to develop diabetic foot at risk as compared to non-smoker (OR 4.11, 95\% Cl: $1.96-8.63$ ) after controlling for other variables. Respondents who were diagnosed with diabetes for more than 10 years had one-time higher risk of developing foot at risk (OR 1.77, $95 \% \mathrm{Cl}: 1.05$ 2.98). Furthermore, respondents with good foot care practice have $87 \%$ lesser risk of developing diabetic foot after controlling for other variables.

Other variables such as race, gender, education level, diabetic control and awareness did not show any significant association with development of foot at risk.

\section{DISCUSSION}

This study revealed that the prevalence of diabetic foot at risk among diabetic type 2 patients attending four primary health clinics in Kuantan was $31.3 \%$ This finding is lower when compared with the another study done in Kuantan by Che Ahmad et al. (2012), where their prevalence of diabetic foot at risk was $57.7 \%$ which was higher. ${ }^{6}$

In this study, it was found that out of the diabetic foot at risk, $85.1 \%$ had dermatological abnormality/ deformity, $8.5 \%$ had sensory neuropathy and $6.4 \%$ had vascular abnormality. This is again in contrast to the study done by Che Ahmad et al. (2012) where dermatological abnormality such as calluses and corns was $45 \%$; sensory neuropathy was $29 \%$ and vascular abnormality was $11 \%{ }^{4}$

The difference between our study and Che Ahmad et. al can be explained by the fact that the majority of respondents from their study were recruited from in-patient wards (53\%) and these patients are expected to have higher number of diabetic foot at risk or complications as compared to patients from outpatient clinic. Their study also found that the 
Table 3: Factors associated with diabetic foot at risk (bivariate analysis).

\begin{tabular}{|c|c|c|c|c|}
\hline \multirow[t]{2}{*}{ Variables } & \multicolumn{2}{|l|}{ Group } & \multirow[t]{2}{*}{ Test stat(df) } & \multirow[t]{2}{*}{$P$ value } \\
\hline & $\begin{array}{l}\text { Normal } \\
n=309 \\
n(\%)\end{array}$ & $\begin{array}{l}\text { At risk } \\
\mathrm{n}=141 \\
\mathrm{n}(\%)\end{array}$ & & \\
\hline $\begin{array}{l}\text { Background characteristics } \\
\text { Age (year) }\end{array}$ & $54.83(11.00) \mathrm{b}$ & $59.72(9.89) \mathrm{b}$ & $-4.52(448)$ & $<0.001^{c}$ \\
\hline $\begin{array}{l}\text { Sex } \\
\quad \text { Male } \\
\text { Female }\end{array}$ & $\begin{array}{l}128(41.4) \\
181(58.6)\end{array}$ & $\begin{array}{l}68(48.2) \\
73(51.8)\end{array}$ & $1.82(1)$ & 0.177 \\
\hline $\begin{array}{l}\text { Race } \\
\text { Non Malay } \\
\text { Malay }\end{array}$ & $\begin{array}{l}39(12.6) \\
270(87.4)\end{array}$ & $\begin{array}{l}28(19.9) \\
113(80.1)\end{array}$ & $4.00(1)$ & 0.045 \\
\hline $\begin{array}{l}\text { Marital status } \\
\text { Single } \\
\text { Married }\end{array}$ & $\begin{array}{l}22(7.1) \\
286(92.9)\end{array}$ & $\begin{array}{c}8(5.7) \\
133(94.3)\end{array}$ & $0.34(1)$ & 0.563 \\
\hline $\begin{array}{l}\text { Educational level } \\
\text { No formal education } \\
\text { Formal education }\end{array}$ & $\begin{array}{l}15(4.9) \\
294(95.1)\end{array}$ & $\begin{array}{l}12(8.5) \\
129(91.5)\end{array}$ & $2.30(1)$ & 0.130 \\
\hline $\begin{array}{l}\text { Income status } \\
\text { Low } \\
\text { Medium } \\
\text { High }\end{array}$ & $\begin{array}{l}183(59.2) \\
98(31.7) \\
28(9.1)\end{array}$ & $\begin{array}{l}90(63.8) \\
40(28.4) \\
11(7.8)\end{array}$ & $0.87(2)$ & 0.647 \\
\hline $\begin{array}{l}\text { Smoking status } \\
\text { Non smoker } \\
\text { Smoker }\end{array}$ & $\begin{array}{l}292(94.5) \\
17(5.5)\end{array}$ & $\begin{array}{l}117(83.0) \\
24(17.0)\end{array}$ & $15.52(1)$ & $<0.001$ \\
\hline $\begin{array}{l}\text { Smoking duration } \\
\quad<10 \text { years } \\
\quad>10 \text { years }\end{array}$ & $\begin{array}{c}7(41.2) \\
10(58.8)\end{array}$ & $\begin{array}{l}11(45.8) \\
13(54.2)\end{array}$ & $0.08(1)$ & 0.767 \\
\hline $\begin{array}{l}\text { Duration of DM } \\
\quad<10 \text { years } \\
\quad>10 \text { years }\end{array}$ & $\begin{array}{l}261(84.5) \\
48(15.5)\end{array}$ & $\begin{array}{l}98(69.5) \\
43(30.5)\end{array}$ & $13.44(1)$ & $<0.001$ \\
\hline $\begin{array}{l}\text { DM Control } \\
\text { Control } \\
\text { Un-control }\end{array}$ & $\begin{array}{l}60(19.4) \\
249(80.6)\end{array}$ & $\begin{array}{c}35(24.8) \\
106(75.2)\end{array}$ & $1.70(1)$ & 0.192 \\
\hline $\begin{array}{l}\text { Mode of } \\
\text { treatment } \\
\text { Non- insulin } \\
\text { Insulin }\end{array}$ & $\begin{array}{l}189(66.5) \\
120(72.3)\end{array}$ & $\begin{array}{l}95(33.5) \\
46(27.7)\end{array}$ & $1.60(1)$ & 0.205 \\
\hline $\begin{array}{l}\text { BMI } \\
\text { Normal } \\
\text { Overweight } \\
\text { Obese }\end{array}$ & $\begin{array}{l}32(10.4) \\
99(32.0) \\
178(57.6)\end{array}$ & $\begin{array}{l}12(8.5) \\
40(28.4) \\
89(63.1)\end{array}$ & $1.26(2)$ & 0.534 \\
\hline $\begin{array}{l}\text { Awareness level } \\
\text { Practice level }\end{array}$ & $\begin{array}{l}11.91 \\
(5.52) \mathrm{b} \\
6.20 \\
(1.83) \mathrm{b}\end{array}$ & $\begin{array}{l}13.09 \\
(5.07) \mathrm{b} \\
5.65 \\
(1.95) \mathrm{b}\end{array}$ & $\begin{array}{l}-2.23(293) \\
2.94(448)\end{array}$ & $\begin{array}{l}0.027^{c} \\
0.003^{c}\end{array}$ \\
\hline
\end{tabular}

a Chi square test

b Mean (SD)

$\mathrm{c}$ Independent t-test 
prevalence of neuropathy in diabetes with duration more than 10 years was $59.5 \%$ higher compared to less than 10 years (36.1\%) duration of diabetes. ${ }^{6}$

Table 4 Factors Associated with Diabetic Foot at Risk $(n=450)$

\begin{tabular}{|c|c|c|}
\hline Variables & $\mathrm{OR}(95 \% \mathrm{Cl})$ & OR(95\%Cl) \\
\hline $\mathrm{Age}^{\mathrm{C}}$ & $1.04(1.01-.06)$ & $0.002^{*}$ \\
\hline $\begin{array}{l}\text { Race } \\
\text { Non- Malay } \\
\text { Malay }\end{array}$ & $0.78(0.43-.38)$ & 0.388 \\
\hline $\begin{array}{l}\text { Gender } \\
\text { Male } \\
\text { Female }\end{array}$ & $1.04(0.99-.08)$ & 0.855 \\
\hline $\begin{array}{l}\text { Education Level } \\
\text { No formal education } \\
\text { Formal education }\end{array}$ & $1.04(0.30-.63)$ & 0.415 \\
\hline $\begin{array}{l}\text { Smoking status } \\
\text { Non smoker } \\
\text { Smoker }\end{array}$ & $4.11(1.96-.63)$ & $<0.001^{*}$ \\
\hline $\begin{array}{l}\text { Duration of DM } \\
\quad \leq 10 \text { years } \\
>10 \text { Years }\end{array}$ & $1.77(1.05-.99)$ & 0.033 \\
\hline $\begin{array}{l}\text { DM control } \\
\text { Control } \\
\text { Uncontrolled }\end{array}$ & $0.87(0.51-.47)$ & 0.592 \\
\hline Practice Level $^{c}$ & $0.87(0.77-.98)$ & $0.021 *$ \\
\hline Awareness Level $^{\mathrm{C}}$ & $1.04(0.99-.08)$ & 0.061 \\
\hline
\end{tabular}

Similar studies in outpatient settings in Jordan and Ethiopia showed lower prevalence of diabetic foot at risk which was $17.2 \%$ and $13.6 \%$ respectively. ${ }^{11,12}$ However another study done in PPUKM outpatient clinic gave a higher prevalence of foot at risk of $42.2 \%{ }^{5}$

The variety of prevalence could be because of the different target populations, sample sizes and classification systems used to categorize the foot at risk. This study uses the Kings Classification to categorize foot at risk while the other studies mentioned above used the IGWDF risk classification. There is another study in India that showed higher prevalence of diabetic foot at risk (51.8\%) according to the IWGDF classification. ${ }^{7}$ These two classifications were the most commonly used to categorize diabetic foot at risk and these differences could be the reason for the variety of prevalence among studies.
In this study, the mean age was $56.36(\mathrm{SD} \pm 10.9)$ years old with the youngest patient being 28 years old and the eldest 82 years old. This is comparable to the age group for diabetes as reported by the National Health and Morbidity Survey (2015), whereby the prevalence of diabetes was increasing in all age groups with the highest prevalence (39.1\%) being among the elderly aged 70 to 74 years. ${ }^{8}$ The increasing trend in diabetes prevalence reflects the increasing risk in developing foot at risk. The mean age for this study is similar with other local studies done in Kuala Terengganu (56.33 years), Kuala Langat Health Centre (52years \pm 10.7 ) and Kuantan $(57.7$ years \pm 10.9$)(4,10,14)$. This mean age was slightly lower than a study done in PPUKM which showed mean age of respondents involved was 60.79 $(\mathrm{SD} \pm 10.3)$ years old. ${ }^{5}$

Majority of the respondents were Malay (85.1\%), followed by Chinese $(8.2 \%)$, Indian $(5.8 \%)$ and others $(0.9 \%)$. According to the Malaysian demographic profile 2018, the Kuantan ethnicity demographics showed the Malays were predominant $79 \%$, Chinese $17.5 \%$ and Indian $3.2 \%$ followed by other groups. Same study outcome was observed in Kuala Terengganu whereby the Malay respondents were highly predominant, $98.1 \% .^{9}$ One would argue that the Malays have the highest prevalence of diabetic foot due to them being the majority, however in Singapore where the Malays are the minority, they were still found to be associated with higher risk for diabetic foot problems. ${ }^{10}$ This may be explained by the lifestyle and increasing trend in obesity among the ethnic group. ${ }^{8}$

This study also revealed that the majority of respondents were female $(56.4 \%)$, married $(93.1 \%)$ and with secondary level of education (53.3\%). This finding shared the same socio-demographic characteristic in the prevalence study on diabetic foot in Jordan and North West Ethiopia. ${ }^{11,} 12$ According to the NHMS 2015, the prevalence of diabetes was higher in females at $18.3 \%(95 \% \mathrm{Cl}$ : $17.2,19.4)$ compared to males at $16.7 \%(95 \% \mathrm{Cl}$ : $15.7,17.8) .{ }^{8}$ Majority of the respondents in this study are from low income group (< RM2300) (60.7\%) and are non-smoker $(90.9 \%)$. It is similar with the study on diabetic foot done in Tanzania and Hospital Kuala Terengganu. ${ }^{9,13}$ Non-smoker was predominant likely because majority of respondents were female, and diabetic patients are usually aware of the risk of smoking to general health. 
Clinical characteristics of respondents involved in this study showed most of them had diabetes for less than 10 years $(79.8 \%)$. This finding was almost similar to the study done in PPUKM where the mean duration of diabetes mellitus were 6.99 years and also in Terengganu where the majority of the respondents were diagnosed with diabetes less or equal to 10 years. ${ }^{5,9}$ In one study done in Pune, the mean duration of diabetes is higher in DFU patient (7.08 years) while the mean duration of diabetes without foot ulcer was 4.01( \pm 2.34$)$ years. ${ }^{14}$ This showed diabetic foot problem is associated with longer duration of diabetes.

Majority of respondents $(63.1 \%)$ in this study were on non-insulin therapy (oral hypoglycemic therapy) and majority $(\mathbf{7 8 . 9 \% )}$ of them had poor diabetic control. This finding is almost similar to NHMS report 2015 in which $79.1 \%$ of the diabetics on survey were on oral anti diabetic agent and $25.1 \%$ of them were on insulin. This finding is also similar to other studies in Kuala Lumpur and India. 5,15

In this study, age was a significant risk factor identified in association with development of diabetic foot at risk. Studies have shown that significant associated factors for peripheral neuropathy among newly diagnosed T2DM were age and presence of retinopathy. The risk for neuropathy increased with age and for every 1 -year increase in age, there will be 1.11 times odds of having neuropathy compared to non-neuropathy. ${ }^{24}$ This finding also correspond to other studies done by Vibha et al. (2018) and Al-Rubeaan (2018) that showed advancing age was significantly associated with DFS. ${ }^{15,16}$ One study done in PPUKM also showed similar finding. ${ }^{5}$ However, in other study showed age was not a significant risk factor for diabetic foot problem in a study done in Egypt ${ }^{17}$ and Pune, India. ${ }^{14}$

Other important risk factor for diabetic foot at risk identified in this study was smoking status. This study showed a smoker has four times risk of having diabetic foot problem compared to non-smoker. Similar finding in one study showed that risk of DFUs were six times more in smokers than non-smokers ( $P$ $<0.001, \mathrm{OR}=6) .{ }^{14}$ One interesting finding regarding smoking in a study done by Faridah \& Azmi (2008) showed that smokers developed ulcers earlier than non-smokers. Physiologically, smoking leads to poor blood flow in the legs that leads to infections, ulcer and possible limb amputation. There were, however, other studies that showed insignificant correlation between smoking and risk of diabetic foot problem. ${ }^{18,19}$

This study has shown that duration of diabetes more than 10 years had one-time risk of developing foot at risk. This is again was similar to a study done by Che Ahmad (2012) whereby the prevalence of foot at risk is higher in diabetic with duration more than 10 years (59.9\%). This result is also consistent with the studies conducted in Saudi Arabia and Egypt where in their study there was a statistically significant trend for the increase in the prevalence of diabetic foot disorders with the increase of the duration of diabetes mellitus among the study population $(p<$ 0.001). ${ }^{17,20}$ A study done in India found that subjects having diabetes mellitus for more than 10 years are 3.7 times more likely to develop DFS compared to subjects with duration less than 5 years. (OR: 3.77, Cl: 2.53-5.62). ${ }^{15}$

Respondents in this study who had higher foot care practice scores were found to have $85 \%$ lesser risk of developing diabetic foot compared to respondents who had poor foot care practice scores. This is supported by a study in North West Ethiopia that showed those diabetic patients who had not practiced foot self-care were 2.52 times more likely to develop diabetic foot ulcer than those diabetic patients who had practiced foot self-care (AOR= 2.52; $95 \% \mathrm{Cl}: 1.21,6.53) .{ }^{11}$ A study done in Iraq showed no significant correlation between foot care practice and development of diabetic foot problem. ${ }^{21}$

Awareness on diabetic foot problem is crucial for early detection of symptoms related to diabetic foot problem in order to halt the progress to ulcer, gangrene and amputation. This study showed that respondents who had foot at risk had higher level of awareness. One possible explanation is that the respondents who had diabetic foot at risk received more information about diabetic foot care from diabetic educator and had more frequent follow-ups to prevent the progress to ulcer. This is supported by a study in Tanzania that showed level of knowledge or awareness influence by longer duration of diabetes as they are likely to have repeated education sessions. ${ }^{13}$ 
Interestingly, most respondents (59.6\%) in this study had poor foot care practice despite having good awareness. Majority of other studies which focused on knowledge of diabetic foot care, revealed poor knowledge or awareness towards diabetic foot problem leading to poor foot care practice. However, there are some studies which showed higher score of knowledge or awareness level that does not lead to good foot care practice. For example, in a study done in a Saudi Hospital assessing knowledge; attitude and practice of which their participants had good education and favorable attitudes towards diabetic foot care, but the results showed that a significant number of diabetic patients (26\%) had diabetic foot. ${ }^{22}$ Similar result was observed in a study done by Jindasa et al (2011) and Mariam et al. (2017), whereby more than $50 \%$ of the participants had good knowledge on foot care, but the level of practice of the foot care principles were poor. Regular foot observation was followed by $65.5 \%$ of respondents. But the rest of the principles were neglected by more than $50 \%$ of study sample. Therefore, it can be concluded that good knowledge does not guarantee good practice if patients do not implement the knowledge into practice. ${ }^{9}$

\section{CONCLUSION}

The prevalence of diabetic foot at risk in this study is quite alarming as compared to other studies done focusing at primary care clinics. This study has confirmed the importance of previously known risk factors for diabetic foot complications. Advancing age, being a smoker, and those who had diabetes for more than 10 years are risk factors associated with diabetic foot at risk in this study. Since those risk factors are highly prevalent in our diabetic population, primary and secondary prevention programs are urgently needed to minimize both morbidity and cost from this chronic complication. Thus, recognition of its risk factors, early screening, education and early intervention by health care personnel plays a very important role in preventing diabetic foot complication. Parallel to that, a sustainable patient education and compliance towards practice of foot care at primary care level should be more emphasized to ensure good foot care practice implementation. Patient's education regarding foot care and footwear is crucial in reducing risk of any injury that can lead to ulcer formation.

\section{CONFLICT OF INTEREST}

The author declare that they have no conflicts of interest

\section{AUTHORS' CONTRIBUTION}

All authors have made contribution to this work.

\section{ACKNOWLEDGEMENT}

This research is supported by the International Islamic University Malaysia research initiative grant scheme (RIGS17-046-0639).

\section{REFERENCES}

1. World Health Organization. Global Report on Diabetes. Isbn [Internet]. 2016;978:88.

Available from: http://www.who.int/about/ licensing/\%5Cnhttp://apps.who.int/iris/ bitstream/10665/204871/1/9789241565257_en g.pdf

2. Dr. Feisul im, dr. Soraya a. National diabetes registry report.

National_diabetes_registry_report. 2013; vol_1.

3. Aziz Z, Lin WK, Nather A, Huak CY, Chan YH. Predictive factors for lower extremity amputations in diabetic foot infections. Diabet Foot Ankle [Internet]. 2011;2(January 2005):16. Available from: http://www.embase.com/ search/results? subaction=viewrecord\&from=export\&id $=\mathrm{L} 36402$ 4255\%5Cnhttp://diabeticfootandankle.net/ index.php/dfa/article/view/7463/pdf\% 5Cnhttp://dx.doi.org/10.3402/dfa.v2i0.7463

4. Armstrong DG. Diabetes and Foot Problems NIDDK. National Intitute of Diabetes and Digestive and Kidney Disease. National Institute of Health; 2017.

5. Jamani NA, Muhammad NA, Jaafar A, Ahmad S, Tohit N. Foot Problem And Foot Care Practices Among Diabetic Patients In A Primary Care Clinic, Kuala Lumpur. Int Joirnal Allied Heal Sci. 2018;2(3):435-44.

6. Che Ahmad A, Mustafa NF, Alias N, Abdul Aziz NA, Ayeop MAS. ACA_Evalu Diab Foot Assessment_25032016. 2012.

7. Jinadasa CVM, Jeewantha M. SP5-14 A study to determine the knowledge and practice of foot care in patients with chronic diabetic ulcers. $J$ Epidemiol Community Heal [Internet]. 2011;65 (Suppl 1):A449-A449. Available from: http:// jech.bmj.com/cgi/doi/10.1136/ jech.2011.142976p.50 
8. Institute for Public Health. National Health and Morbidity Survey 2015 (NHMS 2015). Vol. II: Non-Communicable Diseases, Risk Factors \& Other Health Problems. Ministry of health. 2015. 1-291 p.

9. Muhammad-lutfi AR, Zaraihah MR, Anuarramdhan IM. Knowledge and Practice of Diabetic Foot Care in an In- Patient Setting at a Tertiary Medical Center. Malaysian Orthop J. 2014;8(3):22-6.

10. Nather A, Siok Bee C, Keng Lin W, Qi Odelia KS, Yiong Huak C, Xinyi L, et al. Socioeconomic profile of diabetic patients with and without foot problems. Diabet Foot Ankle [Internet]. 2010;1(5523):1-6. Available from: http:// diabeticfootandankle.net/index.php/dfa/ article/view/5523

11. Mariam TG, Alemayehu A, Tesfaye E, Mequannt W, Temesgen K, Yetwale F, et al. Prevalence of Diabetic Foot Ulcer and Associated Factors among Adult Diabetic Patients Who Attend the Diabetic Follow-Up Clinic at the University of Gondar Referral Hospital, North West Ethiopia, 2016: Institutional-Based Cross-Sectional Study. J Diabetes Res. 2017;2017.

12. Seid A, Tsige Y. Knowledge, Practice, and Barriers of Foot Care among Diabetic Patients Attending Felege Hiwot Referral Hospital, Bahir Dar , Northwest Ethiopia. Adv Nurs. 2015;2015(2015):1-7.

13. Chiwanga FS, Njelekela MA. Diabetic foot: prevalence, knowledge, and foot self-care practices among diabetic patients in Dar es Salaam, Tanzania - a cross-sectional study. J Foot Ankle Res [Internet]. 2015;8:20. Available from: http://www.ncbi.nlm.nih.gov/ pubmed/26064190\%5Cnhttp:// www.pubmedcentral.nih.gov/ articlerender.fcgi?artid=PMC4462176

14. Nongmaithem, M., Bawa, A. P., Pithwa, A. K., Bhatia, S. K., Singh, G., \& Gooptu, S. (2016). A study of risk factors and foot care behavior among diabetics. Journal of family medicine and primary care, 5(2) 399-403. A study of risk factors and foot care behavior among diabetics. India: PMC; 2016. p. J Family Med Prim Care. 2016 Apr-Jun; 5(2): 399-40.

15. Vibha SP, Kulkarni MM, Ballala ABK, Kamath A, Maiya GA. Community based study to assess the prevalence of diabetic foot syndrome and associated risk factors among people with diabetes mellitus. 2018;1-9.
16. Al-Rubeaan K, Al Derwish M, Ouizi S, Youssef AM, Subhani SN, Ibrahim HM, et al. Diabetic Foot Complications and Their Risk Factors from a Large Retrospective Cohort Study. Santanelli, di Pompeo d'Illasi $F$, editor. PLoS One [Internet]. 2015 May 6 [cited 2017 Feb 27];10 (5):e0124446. Available from: http:// dx.plos.org/10.1371/journal.pone.0124446

17. Gaber N, Gamal H, Rohoma KH. Prevalence of diabetic foot disorders and related risk factors among Egyptian subjects with diabetes. 2014;9:297-303.

18. Atosona A. Prevalence and Determinants of Diabetic Foot Ulcers and Lower Extremity Amputations in Three Selected Tertiary Hospitals in Ghana. 2019;2019.

19. Nather A, Bee CS, Lin WK, Odelia KSQ, Chan $\mathrm{YH}$, Xinyi L, et al. Socioeconomic profile of diabetic patients with and without foot problems. Diabet Foot Ankle. 2010;1.

20. Al-Rubeaan K, Al Derwish M, Ouizi S, Youssef AM, Subhani SN, Ibrahim HM, et al. Diabetic Foot Complications and Their Risk Factors from a Large Retrospective Cohort Study. Santanelli, di Pompeo d'Illasi F, editor. PLoS One [Internet]. 2015 May 6 [cited 2017 Feb 27];10 (5):e0124446. Available from: http:// dx.plos.org/10.1371/journal.pone.0124446

21. Saber HJ, Daoud AS. Knowledge and practice about the foot care and the prevalence of the neuropathy among a sample of type 2 diabetic patients in Erbil , Iraq. 2018;

22. Al-hariri MT, Al-enazi AS, Alshammari DM, Bahamdan AS, Al-khtani SM, Al-abdulwahab AA. Descriptive study on the knowledge, attitudes and practices regarding the diabetic foot. $\mathrm{J}$ Taibah Univ Med Sci [Internet]. 2017;12(6):4926. Available from: https://doi.org/10.1016/ j.jtumed.2017.02.00123. Faridah K, Azmi M. Retrospective Study of Predictors for Foot Ulceration among Diabetic Patients Attending Kuala Langat Health Centre from 1999 to 2008. J Community Health. 2008;15(2):43-59.

24. Ms A, Hi A, Juwita S. Risk Factor of Peripheral Neuropathy among Newly Diagnosed Type 2 Diabetic Patients in Primary Care Clinic. 2012;4 (11):1858-67.

25. Jain AKC, Joshi S. Diabetic Foot Classifications $\square$ : Review of Literature. 2013;2 (3):715-21. 